\title{
Engineering Test of Gas Ablation Agent in Mine Gas Control
}

\author{
Guo Aijun ${ }^{1}$, Yang Haorui ${ }^{1, ~}$, Zhao Qingzhen ${ }^{2}$, Sun Hanying ${ }^{1}$, Zhai Zhiwei ${ }^{2}$ \\ ${ }^{1}$ General Prospecting Institute China National Administration of Coal Geology, Beijing, China \\ ${ }^{2}$ Shanxi Institute of Energy, Shanxi, China
}

Email address:

yhr0325@163.com (Yang Haorui)

*Corresponding author

\section{To cite this article:}

Guo Aijun, Yang Haorui, Zhao Qingzhen, Sun Hanying, Zhai Zhiwei. Engineering Test of Gas Ablation Agent in Mine Gas Control. Journal of Energy and Natural Resources. Vol. 10, No. 2, 2021, pp. 46-52. doi: 10.11648/j.jenr.20211002.12

Received: April 26, 2021; Accepted: June 2, 2021; Published: June 4, 2021

\begin{abstract}
Gas is a major threat to the safety of coal mine production, Gas Ablation Agent is a major component of methane oxidation bacteria, added a special catalyst, used to eliminate the high concentration of gas biological solvents, gas reduction speed, low cost, non-toxic harmless characteristics. Gas Ablation Agent can quickly decompose or convert gas into other harmless substances, eliminate or reduce gas in coal seams, reduce gas pressure and gas content, so as to eliminate the prominent risk of coal and gas, is a new biochemical technology to control coal mine gas. After 24 hours, the gas content decreased by an average of $3.64 \mathrm{~m}^{3} / \mathrm{t}$ and $2.24 \mathrm{~m}^{3} / \mathrm{t}$ respectively. Gas ablation microorganisms, while breaking down methane, can promote the rapid decomposition of methane adsorbed in coal bodies. Compared with the conventional excavation method, the number of construction drilling holes decreased by about $92 \%$, the total number of digging days decreased by 59 days, and the efficiency of coal extraction increased by 3.2 times. Gas Ablation Agent is an effective and environmentally friendly technical method to control gas, which is of great practical significance for the prevention and control of coal and gas, and the promotion of efficient and safe production.
\end{abstract}

Keywords: Gas Ablation Agent, Biochemical Technology Gas Control, Gas Mine, Rock Cross-cut Coal Uncovering

\section{Introduction}

China is one of the most prominent coal and gas countries in the world, there are more than 20 provinces (regions) in the mine has occurred prominent, among them, Sichuan, Chongqing, Hunan, Liaoning, Henan, Guizhou, Anhui, Jiangxi and other provinces have more serious coal mine outbursts, not only the number of outstanding times, but also strong. And most of the outstanding occurred in the coal lane excavation, the strongest mainly occurred in the stone gate to expose coal [1].

Currently, there are two different highlight technological innovation ways in preventing coal and gas outburst. The first is the physical permeation and extraction of high gas, strong adsorption and low breathable coal seams. These include: ground coal seam gas extraction, protective layer extraction, water slits, hydraulic fracturing (underground, ground), $\mathrm{CO}_{2}$ pre-cracking, deep-hole blasting, hydro-punching, etc. [1-6]; The second way is using the biochemical methods to eliminate or reduce the gas in coal seams which is a forward-looking new way of gas treatment at home and abroad [7-12].

Using microbial technology to eliminate or reduce coal seam gas is through screen and breed of microorganisms that can decompose and transform gas in nature. These highly reactive microorganisms are injected into coal seams. The gas in the coal seam is decomposed or transformed into other harmless substances. Eliminate or reduce gas in coal seams, reduce gas pressure and gas content. Thus, the danger of coal and gas outburst can be eliminated.

In China, the use of microbial technology to treat gas in coal mine safety academic circles has not attracted enough attention, microbial gas treatment research is still in the laboratory experiments and small-scale industrial test stage [8-13]. No continuous large-scale industrial testing has been carried out prior to this project. Through the large-scale engineering practice of microbial gas treatment in Yangquan Coal Sijiazhuang Mine, the research and exploration of microbial technology of gas treatment in China and the exploration of new ways of gas treatment technology in coal mine are not only realistic necessity for gas treatment of 
Yangquan Coal Industry, but also have important guidance and reference for perfecting the outstanding technical system of coal and gas control in China.

\section{The Current Situation of Microbial Gas Treatment Research}

The research on the use of microbial technology to control coal mine gas disasters abroad has achieved some results. In the early 1970s, microbiologists from the Russian Academy of Sciences and researchers from the Moscow Mining Research Institute worked together to develop a biometric gas technology that effectively controlled methane levels in coal mines. This technology has been industrialized in mines in the Donetsk and Kuznetsk coal fields, reducing methane levels by 30-60 percent [7].

At the 4th International Mine Ventilation Conference in 1988, Canadian scholar Chakravoti and others proposed "new technologies to eliminate the risk of gas". During the same period, Australian researchers sprayed methane oxidizing bacteria on coal mine walls with a 66 percent removal rate after 20 days, and American researchers found an acidic marsh environment with an efficient methane-degrading bacteria caused by Bayerink bacteria, which degrades 90 percent of methane in its surroundings [7].

In China, Lu Wang, Dongke Chen and others from Beijing University of Science and Technology, using the M3011 and GYJ3 hybrid strains screened, cultivated and domesticated to do the gas degradation test with 12 gas-containing coal samples extracted from different mining areas and different depths in Pingdingshan, Henan Province. The results showed that the methane content of the test group with methane oxidation bacteria was reduced within $24 \mathrm{~h}$ compared with the reference sample, and the methane content decreased significantly in four coal samples [8-10].

Dr. Yu Haixia (2007) of Zhejiang University studied the use of laboratory-sized biofilm droplet filter towers to purify methane-air mixtures of methane and air in areas slightly larger than gas explosions (methane content of 5\%-16\%), using laboratory-sized biofilm droplets, using a methane oxide mixture system with high efficiency in methane processing, and studying the factors affecting the biodile filter tower and methane treatment effect [11].

Dr. Jiang Hao (2010) of Tsinghua University studied the ability of mixed bacteria to remove methane in laboratory simulation coal seams and biofiltration experiments, and conducted field trials in three mines in Henan Province to inject prepared bacteria into the coal seams and reach saturation, and the effect of methane removal was significant, indicating that the rich methane oxidation hybrid bacteria have the potential to treat gas in coal mines [12].

Dr. Mao Fei (2013) of Chongqing University studied the most suitable growth conditions for the screening, separation purification, identification, gene analysis and large-scale culture of methane oxide bacteria, and verified the performance of methane oxide [13].
Guo Aijun and others (2018) carried out an engineering test study on gas solvent control gas at the Shijiazhuang mine excavation work surface, and through the analysis of the test results, it is concluded that gas solvent is an effective and environmentally friendly new coal mine gas treatment technology [14].

\section{Gas Characteristics and Control Measures of Test Coal Mine}

Siijiazhuang Mine is located in Xiyang County, and the mine industrial site is about $7 \mathrm{~km}$ southwest of the county seat. The coal-bearing strata in this mine field include the Middle Carboniferous Benxi Formation, the Upper Carboniferous Taiyuan Formation, and the Lower Permian Shanxi Formation The main coal-bearing strata are the Upper Carboniferous Taiyuan Formation and the Lower Permian Shanxi Formation (average the thickness of the coal-bearing strata is about $60 \mathrm{~m}$ ), the total thickness of the coal-bearing strata is $168.24 \mathrm{~m}$, with a total of 18 coal-bearing layers, the total thickness of the coal seams is $13.46 \mathrm{~m}$, and the coal content coefficient is about $8 \%$. There are coal seams $6,81,84,9$ and 15 that can be mined from top to bottom, with a total thickness of $9.9 \mathrm{~m}$. Among them, No. 15 coal is stable and mineable in the whole area. It is the main mineable coal seam and the first mineable coal seam. The maximum thickness is $7.65 \mathrm{~m}$ and the average thickness is $5.48 \mathrm{~m}$.

2013 mine gas level appraisal results: the absolute gas emission from the mine is $305.01 \mathrm{~m}^{3} / \mathrm{min}$, the drainage volume is $256.63 \mathrm{~m}^{3} / \mathrm{min}$, the mine air exhaust gas volume is $48.38 \mathrm{~m}^{3} / \mathrm{min}$, and the mine drainage rate is $84.1 \%$. The gas emission volume of the working face is $181.5 \mathrm{~m}^{3} / \mathrm{min}$, the drainage volume is $166.41 \mathrm{~m}^{3} / \mathrm{min}$, and the gas drainage rate of the working face is $91.7 \%$. During the construction of the mine, Sijiazhuang Coal and Gas Outburst occurred 2 times. Appraised by the Shenyang Research Institute of China Coal Science and Industry Group, Sijiazhuang Mine is a coal and gas outburst mine, and the $15 \#$ coal seam is a coal and gas outburst coal seam.[15].

Before the test of using gas dissolving agent, the maximum gas content of the ninth cross-tail roadway in the 15116 working face before the pre-drainage was $10.11 \mathrm{~m}^{3} / \mathrm{t}$, the minimum gas content was $7.27 \mathrm{~m}^{3} / \mathrm{t}$, the average gas content was $8.69 \mathrm{~m}^{3} / \mathrm{t}, 108$ drills were constructed, the drilling construction time is 15 days (January 6th, 2014 to January 20th, 2014), the drainage time is 42 days (January 7th-February 17th), and the amount of gas drainage is $35828 \mathrm{~m}^{3}$. After pumping, the maximum gas content is $7.86 \mathrm{~m}^{3} / \mathrm{t}$, the minimum gas content is $6.76 \mathrm{~m}^{3} / \mathrm{t}$, the average gas content is $7.31 \mathrm{~m}^{3} / \mathrm{t}$, the average gas content is reduced by $1.38 \mathrm{~m}^{3} / \mathrm{t}$, the tunneling is $30 \mathrm{~m}$, it takes 27 days, a total of 70 days (drilling, drainage, Tunnelling) [15]. The gas control measures for the uncovering coal at Shimen in the 15301 working face are basically the same as those in the 15116 working face. 


\section{Characteristics and Technology of Microbial Gas Dissolving Agent}

\subsection{Microbial Gas Dissolver}

Gas dissolving solvent is a kind of high-concentration biological solvent used to eliminate gas with the main component of methane oxidizing bacteria and added special catalyst. It is a brand-new biochemical technology for the treatment of coal mine gas. It has fast gas reduction speed and low cost, Non-toxic and harmless features. After injecting the gas dissolving solvent into the coal seam through high pressure, it can swallow $40 \%$ to $70 \%$ of the gas in the coal seam in about 2 hours, forming a non-toxic, harmless and non-influencing lipid organic matter on the coal quality, which adheres to the molecular surface of the coal. And cracks and the surface layer of the coal in the bedding, thereby greatly reducing the gas content and gas pressure of the coal seam, achieving the purpose of eliminating the dynamic phenomenon of gas outburst and reducing the amount of gas emission. The gas dissolution rate reaches more than $40 \%$ to $70 \%$, which is an effective complement to the existing gas treatment method in coal mine.
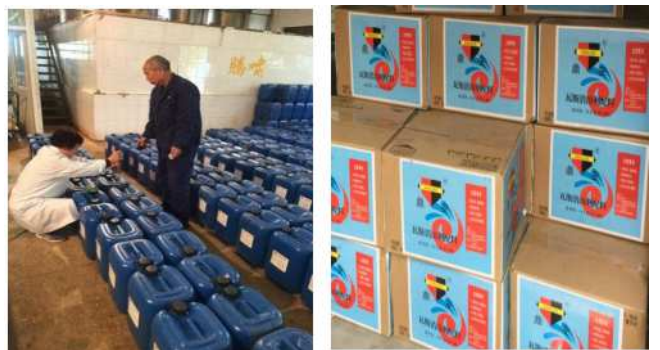

Figure 1. Gas ablation agent.

The gas ablation agent is composed of two parts, one is the base material color is brown, the $\mathrm{PH}$ value is 5.5, the other is the catalyst, the color is white. The product is transported to the liquid injection site of the underground mining face. The small materials corresponding to the number of barrels according to the amount of liquid injection are unpacked and poured into the storage tank. The total addition amount is calculated according to the addition amount of a bag of material activation solution and added to the activation solution. After stirring, wait for 30 minutes, then add all the basic liquid in the barrel, and add clean water in an amount 3-5 times the weight of the gas ablation agent for blending. It can be used after stirring and emulsification.

\subsection{Liquid Technology Equipment and Technology}

The process flow of microbial gas desolvent injection into the coal seam is: technical plan formulation drilling sealing Connecting pipeline adjusting equipment distributing agents opening pump and injecting liquid effect inspection drilling (stopping). The liquid injection system is composed of BPW80/31.5 spray pump, pressure gauge, flow meter, pressure relief valve, flow control valve, high pressure water pipe, etc. (Figure 2). The plugging equipment adopts 3NB-150/7-75 mud pump. In order to ensure the effect of liquid injection pressure, the plugging cement slurry needs to be sealed by high pressure.

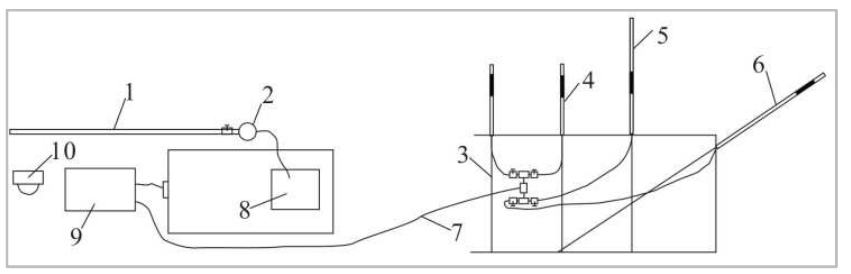

Figure 2. Schematic diagram of gas ablation agent injection system.

\section{Cross-measure Cutting Coal Working Face Test}

Using microbial gas dissolvents, We did two experiments in Sijiazhuang mine cross-measure cutting coal. The test sites are located respectively 15301 working face first crossing of Fengfeng Pedestrian Lane and 15116 working face the eighth crossing inner interlocked gas tail road.

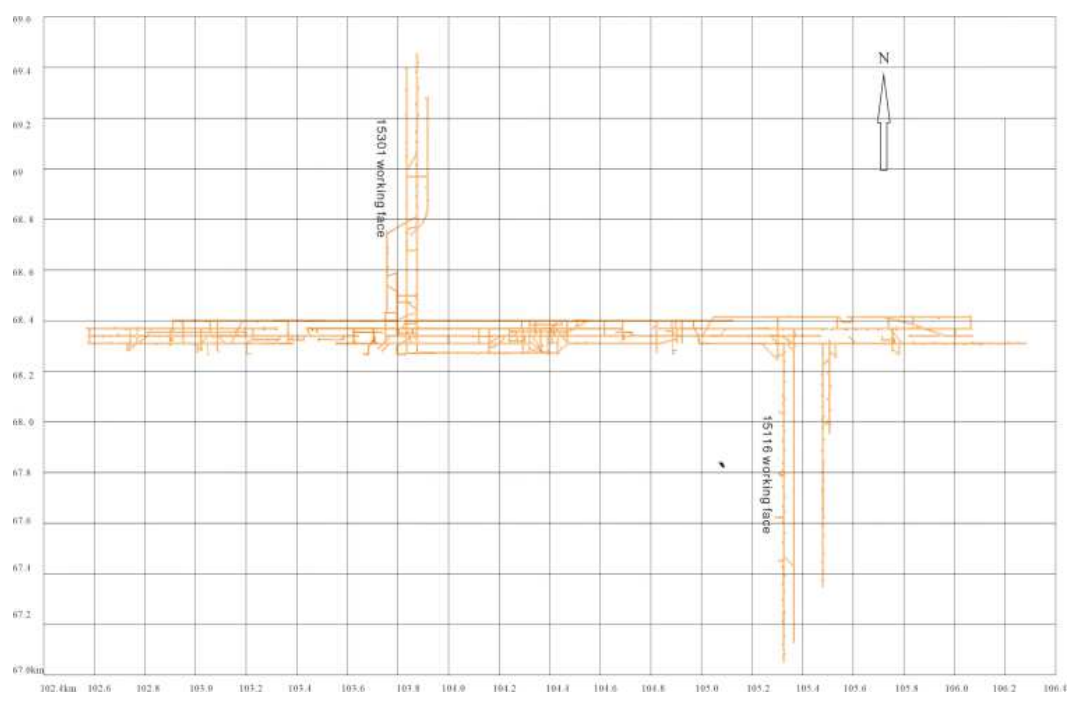

Figure 3. 15301 and 15116 working face location map. 
The coal seam structure of 15301 working face is complex. Intake airway and inner interlocked gas tail road are located above the roof of No. 15 coal seam, spacing $6 \mathrm{~m}$. It generally contains 2-3 layers of dirt band. The types of coal rocks are semi-bright type and bright type. The nature is fragile and easily broken, and the upper part of the luster is dark, and more dark coal. Lithology of roof and floor of coal seam are siltstone, aluminum mudstone and sandy mudstone. The dip angle of coal seam is 3-15 degrees, $5.19 \mathrm{~m}$ thickness. The content, pressure and emission of gas in working face decrease from north to south. Gas content $8-9 \mathrm{~m}^{3} / \mathrm{t}$, gas pressure
0.1-0.3MPa, gas emission $18-20 \mathrm{~m}^{3} / \mathrm{t}$.

The coal seam structure of 15116 working face is simple. Inner interlocked gas tail road are located above the roof of No. 15 coal seam, spacing $6 \mathrm{~m}$. It generally contains 2-3 layers of dirt band. The dirt band is lump and powdery. The types of coal rocks are bright type. Lithology of roof and floor of coal seam are fine grained sandstone, mudstone and sandy mudstone. The dip angle of coal seam is 3-6 degrees, $6.25 \mathrm{~m}$ thickness. The data of gas content, pressure and emission in working face are relatively high. Gas content $9-16 \mathrm{~m}^{3} / \mathrm{t}$, gas pressure 0.3-0.74MPa, gas emission $18-20 \mathrm{~m}^{3} / \mathrm{t}$

Table 1. Injection hole and check hole parameters in 2 tests.

\begin{tabular}{|c|c|c|c|c|c|c|}
\hline test phase & drilling properties & hole number & angle $\left(^{\circ}\right)$ & azimuth angle & drilling depth & drilling tunnels \\
\hline \multirow{9}{*}{ phase one } & \multirow{5}{*}{ test hole } & $1 \#$ & -43 & $\mathrm{~N}^{\circ}$ & 14 & \multirow{5}{*}{$\begin{array}{l}15310 \text { working face } \\
\text { return air system lane }\end{array}$} \\
\hline & & $2 \#$ & -22 & $\mathrm{~N} 0^{\circ}$ & 27 & \\
\hline & & $3 \#$ & -43 & $\mathrm{~N} 0^{\circ}$ & 14 & \\
\hline & & $5 \#$ & -33 & $\mathrm{~N} 0^{\circ}$ & 20 & \\
\hline & & $6 \#$ & -20 & $\mathrm{~N} 0^{\circ}$ & 35 & \\
\hline & \multirow{4}{*}{ Check hole } & Check1\# & -20 & SW $26^{\circ}$ & 33 & \multirow{4}{*}{$\begin{array}{l}15310 \text { working face } \\
\text { return air system lane }\end{array}$} \\
\hline & & Check3\# & -20 & SW26 ${ }^{\circ}$ & 33 & \\
\hline & & Check4\# & -20 & $\mathrm{NW} 26^{\circ}$ & 36 & \\
\hline & & Check5\# & 23 & NE30 $30^{\circ}$ & 54 & \\
\hline \multirow{17}{*}{ phase two } & \multirow{6}{*}{ test hole } & Check6\# & 23 & $\mathrm{NE} 30^{\circ}$ & 50 & \multirow{6}{*}{$\begin{array}{l}15310 \text { working face inner } \\
\text { interlocked gas tail road }\end{array}$} \\
\hline & & $1 \#$ & -12 & $\mathrm{NW} 15^{\circ}$ & 50 & \\
\hline & & $2 \#$ & -48 & $\mathrm{NW} 15^{\circ}$ & 12 & \\
\hline & & $3 \#$ & -19 & $\mathrm{~N} 0^{\circ}$ & 33 & \\
\hline & & $4 \#$ & -28 & $\mathrm{~N} 0^{\circ}$ & 20 & \\
\hline & & $6 \#$ & -48 & $\mathrm{SW} 15^{\circ}$ & 12 & \\
\hline & \multirow{5}{*}{ Check hole } & Check1\# & -15 & $\mathrm{~W} 0^{\circ}$ & 50 & \multirow{6}{*}{$\begin{array}{l}15116 \text { working face inner } \\
\text { interlocked gas tail road }\end{array}$} \\
\hline & & Check2\# & -40 & $\mathrm{SE} 31^{\circ}$ & 15 & \\
\hline & & Check3\# & -15 & $\mathrm{~W}^{\circ}$ & 50 & \\
\hline & & Check4\# & -40 & SE31 $1^{\circ}$ & 15 & \\
\hline & & Check5\# & -15 & $\mathrm{~W} 0^{\circ}$ & 50 & \\
\hline & \multirow{6}{*}{ hard hole } & Check6\# & -40 & $\mathrm{SE} 31^{\circ}$ & 15 & \\
\hline & & $7 \#$ & -22 & $\mathrm{~W} 0^{\circ}$ & see $1 \mathrm{~m}$ behind the coal & \multirow{5}{*}{$\begin{array}{l}15116 \text { working face inner } \\
\text { interlocked gas tail road }\end{array}$} \\
\hline & & $8 \#$ & -22 & $\mathrm{~W} 0^{\circ}$ & see $1 \mathrm{~m}$ behind the coal & \\
\hline & & $9 \#$ & -22 & $\mathrm{~W} 0^{\circ}$ & see $1 \mathrm{~m}$ behind the coal & \\
\hline & & $10 \#$ & -22 & $\mathrm{~W} 0^{\circ}$ & see $1 \mathrm{~m}$ behind the coal & \\
\hline & & $11 \#$ & -22 & $\mathrm{~W} 0^{\circ}$ & see $1 \mathrm{~m}$ behind the coal & \\
\hline
\end{tabular}

\subsection{Phase One Test}

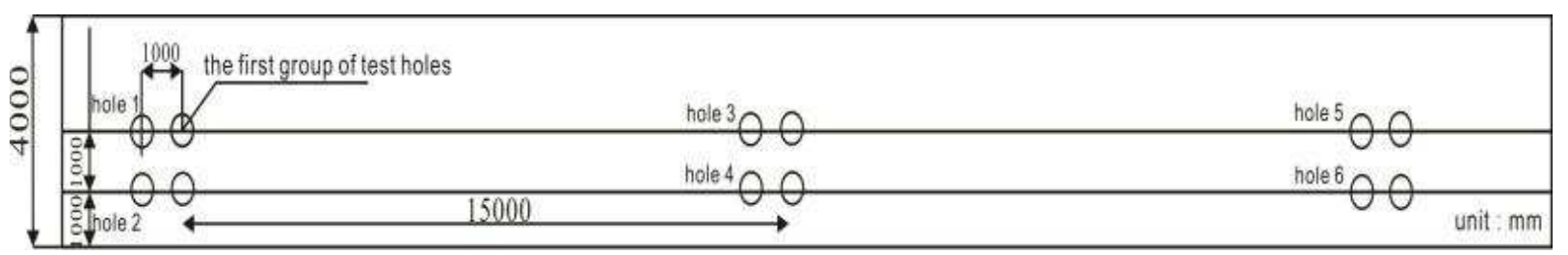

Figure 4. Layout plan of opening hole of No. 1 cross-section uncovering test hole of 15301 intake airway.

Six test holes and six check hole were constructed by microbial gas dissolvents experiment in No. 1 cross-section coal uncovering of 15310 working face. They arranged themselves in two rows above and below, row spacing is $1 \mathrm{~m}$, hole spacing is $15 \mathrm{~m}$. The maximum hole sealing depth is $29 \mathrm{~m}$, minimum depth is $14 \mathrm{~m}$ (figure 4 , table 1). In this test, $3.05 \mathrm{t}$ of microbial gas dissolvent and 30 tons of water was injected, total injection liquid was $33.05 \mathrm{t}$.
After the completion of the first crossing test of the 15301 working face intake airway, we carried out three driving cycles. In the absence of gas emissions, the average residual gas content was $6.68 \mathrm{~m}^{3} / \mathrm{t}$, regional measures meet targets. In three driving cycles, The $\mathrm{K} 1$ value is maximum 1.59 and minimum 0.86. After taking partial measures, the $\mathrm{K} 1$ value reached the standard, we completed three cycles of excavation and uncovering of coal (figure 5, table 2) 
Table 2. K1 value of three uncovering coal.

\begin{tabular}{llll}
\hline test phase & progress & forecast the maximum K1 value & effect check the maximum K1 value \\
\hline \multirow{3}{*}{ phase one } & first cycle & 0.86 & 0.35 \\
& second cycle & 1.59 & 0.42 \\
& third cycle & 1.15 & 0.38 \\
phase two & first cycle & 0.28 & 0.34 \\
& second cycle & 0.72 & 0.36 \\
& third cycle & 0.61 & 0.42 \\
\hline
\end{tabular}

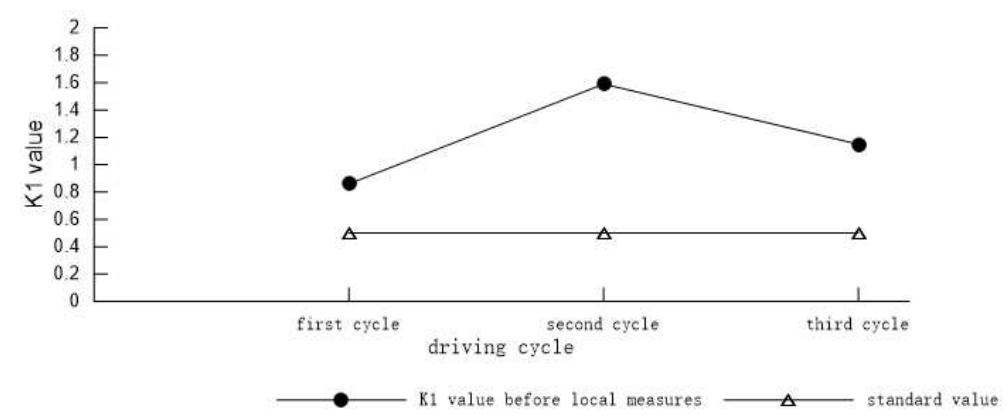

Figure 5. K1 value diagram of the first cross-section uncovering test in intake airway of 15301 working face.

\subsection{Phase Two Test}

The eighth traversing of 15116 inner interlocked gas tail road was constructed with 17 test holes. Among them, there are 6 liquid injection holes, 6 check holes and 5 grouting holes (rock reinforcement). Injection drilling holes are arranged in two rows (The upper and lower rows each have three holes), row spacing $1 \mathrm{~m}$ and hole spacing $12 \mathrm{~m}$. Grouting holes (rock reinforcement) are arranged in a single row with hole spacing of $10 \mathrm{~m}$ (Figure 6, Table 1). When the construction, we first constructed grouting hole, second we seal the hole, finally, we injected cement slurry. 24 hours after the completion of grouting, the injection hole and effect check hole were constructed. In this test, 3.0t of microbial gas dissolvent and 30 tons of water was injected, total injection liquid was $33.0 \mathrm{t}$

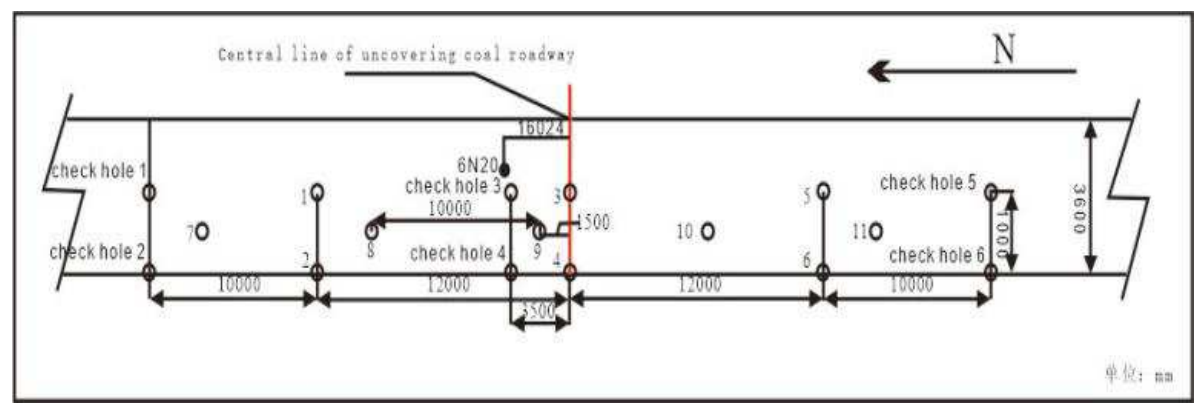

Figure 6. Layout plan of the eighth cross-cutting uncovering test hole in 15116 inner interlocked gas tail road.

After the completion of the eighth crossing test of the 15301 working face inner interlocked gas tail road, we carried out three driving cycles. In the absence of gas emissions, the average residual gas content was $7.01 \mathrm{~m}^{3} / \mathrm{t}$, regional measures meet targets. In three driving cycles, The $\mathrm{K} 1$ value is maximum 0.72 and minimum 0.28 . After taking partial measures, the K1 value reached the standard, we completed three cycles of excavation and uncovering of coal (figure 7, table 2)

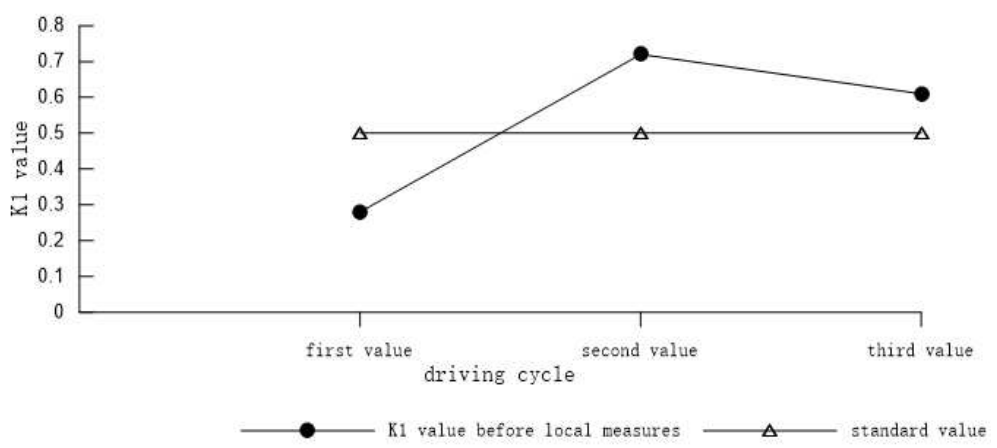

Figure 7. K1 value diagram of the first cross-section uncovering test in 15116 inner interlocked gas tail road. 


\section{Test Effect Analysis}

\subsection{Phase One Test}

The original gas content before liquid injection in the first cross-section coal uncovering of intake airway of 15301 working face was the highest $11.27 \mathrm{~m}^{3} / \mathrm{t}$, the lowest $9.74 \mathrm{~m}^{3} / \mathrm{t}$ and the average $10.32 \mathrm{~m}^{3} / \mathrm{t}$. The residual gas content after liquid injection was the highest $7.10 \mathrm{~m}^{3} / \mathrm{t}$, the lowest $6.18 \mathrm{~m}^{3} / \mathrm{t}$ and the average $6.68 \mathrm{~m}^{3} / \mathrm{t}$. Within 24 hours after the test, gas content decreased by $3.64 \mathrm{~m}^{3} / \mathrm{t}$ on average, the reduction rate was about $35.2 \%$. (Figure 8 )

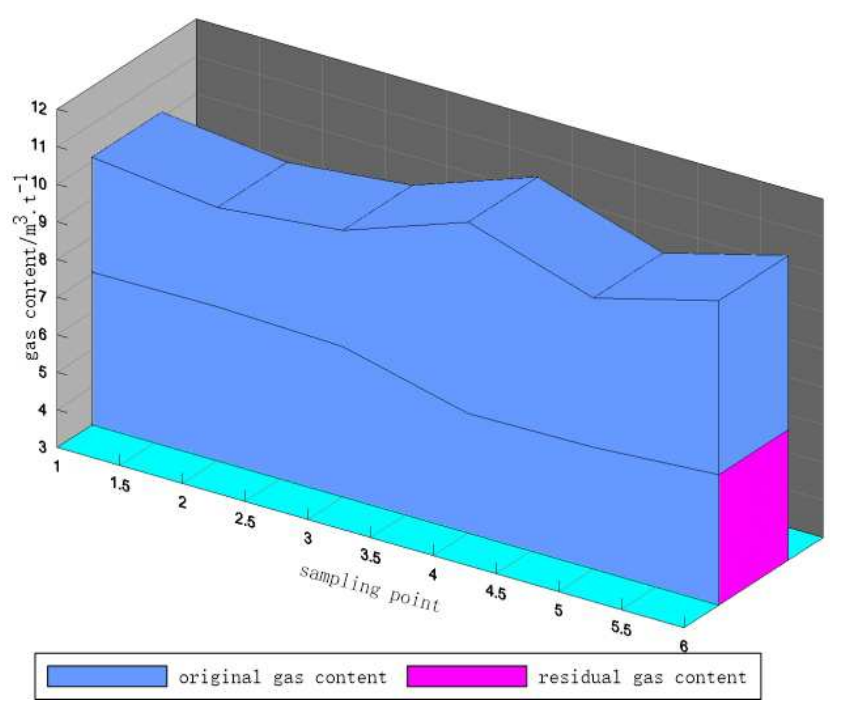

Figure 8. Comparison diagram of original gas content and residual gas content at the first cross-section uncovering coal of 15301 working face intake airway.

\subsection{Phase Two Test}

The original gas content before liquid injection in the eighth cross-section coal uncovering of 15116 working face inner interlocked gas tail road was the highest $9.75 \mathrm{~m}^{3} / \mathrm{t}$, the lowest $8.86 \mathrm{~m}^{3} / \mathrm{t}$ and the average $9.25 \mathrm{~m}^{3} / \mathrm{t}$. The residual gas content after liquid injection was the highest $7.85 \mathrm{~m}^{3} / \mathrm{t}$, the lowest $6.44 \mathrm{~m}^{3} / \mathrm{t}$ and the average $7.01 \mathrm{~m}^{3} / \mathrm{t}$. Within 24 hours after the test, gas content decreased by $2.24 \mathrm{~m}^{3} / \mathrm{t}$ on average, the reduction rate was about $24.2 \%$. (Figure 9 )

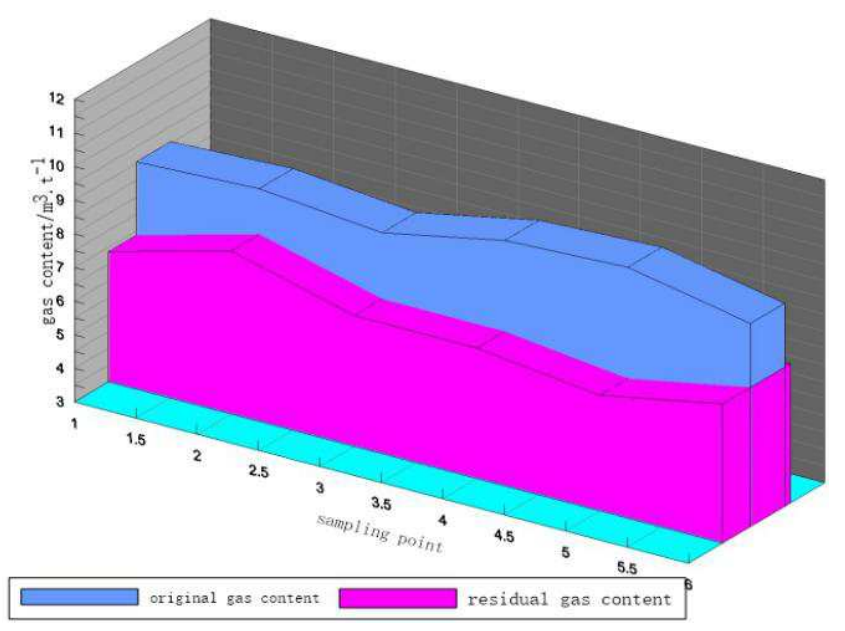

Figure 9. Comparison diagram of original gas content and residual gas content at the eighth cross-section uncovering coal of 15116 working face inner interlocked gas tail road.

\subsection{Comparison of Uncovering Coal Efficiency}

108 drilling holes for uncovering coal were designed by conventional measures (Take 15116 inner interlocked gas tail road as an example). After the gas dissolvents test, the number of drilling holes in construction is 9 . The number of drilling holes under construction is $1 / 12$ of the number of drilling holes under the original extraction method.

The construction time of conventional uncovering coal drilling is 15 days, the pre-pumping time is 42 days, the local measure time is 3 days, the excavation time is 27 days, and the excavation depth is $30 \mathrm{~m}$. The construction time of gas ablation and uncovering coal drilling is 3-5 days, with no pre-pumping time, 3 days for local measures, 20 days for tunneling, and $30 \mathrm{~m}$ drilling footage (Table 3). Compared with the conventional measures for uncovering coal, the conventional measures need 87 days for uncovering coal, and only 26-28 days for gas dissolvents. The efficiency of uncovering coal is increased by 3.2 times, and the technical and economic benefits are remarkable.

Table 3. Comparison of conventional coal excavation method and gas dissolvents elimination test in cross-measure cutting coal.

\begin{tabular}{|c|c|c|c|c|c|}
\hline \multirow[b]{2}{*}{ Regional integrated anti-invasion measures } & \multirow[b]{2}{*}{ Hole depth } & \multicolumn{4}{|c|}{ driving conditions } \\
\hline & & $\begin{array}{l}\text { drilling } \\
\text { number }\end{array}$ & $\begin{array}{l}\text { drilling } \\
\text { construction time }\end{array}$ & $\begin{array}{l}\text { gas drainage } \\
\text { days }\end{array}$ & tunneling days \\
\hline 15116 inner tail nine traverse (original style) & $15-65$ & 108 & 15 & 42 & $27(30 \mathrm{~m}$, cannon driving) \\
\hline Gas dissolvents test method (15301 air inlet cross) & $14-54$ & 9 & 3 & No drainage & $20(25 \mathrm{~m}$, cannon driving) \\
\hline Gas dissolvents test method ( 15116 inner tail eight cross) & $11-50$ & 9 & 5 & No drainage & $20(30 \mathrm{~m}$, cannon driving) \\
\hline
\end{tabular}

\section{Conclusion}

(1) Within 24 hours after the injection of microbial gas ablator, the gas content was significantly reduced without gas drainage or natural discharge. Before the test, the maximum gas content of cross-measure cutting coal face is $11.27 \mathrm{~m}^{3} / \mathrm{t}$, the minimum gas content is $8.86 \mathrm{~m}^{3} / \mathrm{t}$, and the average gas content is $9.79 \mathrm{~m}^{3} / \mathrm{t}$. After the test, the maximum gas content is $7.85 \mathrm{~m}^{3} / \mathrm{t}$, the minimum gas content is $6.18 \mathrm{~m}^{3} / \mathrm{t}$, and the average gas content is $6.85 \mathrm{~m}^{3} / \mathrm{t}$. The average gas content decreased by $2.94 \mathrm{~m}^{3} / \mathrm{t}$. 
(2) It can be seen from the comparison between the conventional excavation method of cross-measure cutting coal and the experimental excavation of gas ablation agent, the number of drilling holes in the method of gas dissolvents treatment is only $1 / 12$ of that in the original drainage method, the total excavation working days decreased by 59 days, uncovering coal efficiency increased by 3.1 times. It greatly reduces the production cost and has remarkable technical and economic benefits.

Using gas ablation agent, large-scale engineering tests were carried out in Yangquan mining area for the first time. Through the three-stage test on the uncovering coal face of Sijiazhuang mine, it is shown that the gas ablation is an effective and environmental protection technology method to control the gas, and it has important economic and social benefits to prevent the coal and gas outburst and realize the safe and efficient mining in Sijiazhuang mine. It also has important guidance and reference significance to study and explore the microbiological technology of gas control in China and to perfect the technical system of coal and gas outburst control in China.

At present, the exploration and research of microbial technology to control coal mine gas has been transformed from laboratory to industrial application in coal mine enterprises. Although domestic and foreign experts, scholars through a large number of experimental studies can fully prove that the use of microbial control of coal mine gas technology is feasible in theory. However, there is still a long way to go before it can be used as a routine measure of coal mine gas control. It is necessary to carry out further scientific research on the mechanism of microbial gas elimination, the adaptation of gas dissolvents to geological conditions, the influence of gas dissolvents on coal quality, the environment, and the integral liquid injection process.

\section{References}

[1] Fu Jianhua, Cheng Yuanping. Situation of Coal and Gas Outburst in China and Control Countermeasures [J]. Journal of Mining \& Safety Engineering, 2007, 24 (3): 253-259.

[2] Yuan Liang, Lin Baiquan, Yang Wei. Research progress and development direction of gas control with mine hydraulic technology in China coal mine $[\mathrm{J}]$. Coal Science and Technology, 2015, 43 (1): 45-49.
[3] Cheng Yuanping, Fu Jianhua, Yu Qixiang. Development of Gas Extraction Technology in Coal Mines of China [J]. Journal of Mining \& Safety Engineering, 2009, 26 (2): 127-139.

[4] Xu Jingde, Yang Xin, Lai Fangfang, et al. Present Situation and Development of Permeability Improvement Technology for Enhanced Gas Drainage in Our Coal Mines [J]. Mining Safety \& Environmental Protection, 2014, 41 (4): 100-103.

[5] He Tiancai, Wang Baoyu, Tian Yongdong. Development and issues with coal and coal-bed methane simultaneous exploitation in Jincheng mining area [J]. Journal of China Coal Society, 2014, 39 (9): 1779-1785.

[6] Li Zhiqiang. Application of $\mathrm{CO}_{2}$ Presplit Blasting Anti-reflection Technology in Gas Extraction [J]. Shanxi Coking Coal Science \& Technology, 2014, 7: 30-31.

[7] Hou Chentao. Research prospect of applying microorganism in controlling coal gas [J]. COAL GEOLOGY \&EXPLORATION, 2007, 35 (4): 30-33.

[8] Wang Lu, Jin Longzhe, Chen Dongke. Research Prospect of Applying Microorganism in Controlling Coal Gas [J]. China Safety Science Journal, 2005, 15 (10): 97-99.

[9] Cheng Dongke, Wang Lu, Jing Longzhe, et al. Research Prospect of Applying Microorganism in Controlling Coal Gas [J]. Mining Safety \& Environmental Protection, 2005, 32 (6): 49-52.

[10] Chen Dongke, Wang Lu, Jin Longzhe, et al. The preliminary research on coal-bed gas degradation by microorganism [J]. Journal of China Coal Society, 2006, 31 (5): 607-609.

[11] Xu Haixia. Studies on Bio-oxidizing Methane in Coal Mines with Microbial Technology [D]. Hangzhou: Zhejiang University, 2007.

[12] Jiang Hao. Enrichment Culture of Mixed Methanotrophic Community and Its Application in Coal Mine Gas Control [D]. Beijing: Tsinghua University, 2010.

[13] Mao Fei. Research on the Theory and Application of Gas Control by Microorganism In the Coal Seam [D]. Chongqing: Chongqing University, 2013.

[14] Guo Aijun, Linghu Jianshe, Zhao Qingzhen, Cao Daiyong. Application of Microbial Gas Ablation Agent in Gas Control in Sijiazhuang Coal Mine [J]. Coal Technology, 2018, 37 (1): 128-130.

[15] Yangquan Coal Industry Co. Ltd The final research report on the promotion and application of biosynthetic gas dissolvents in the elimination of coal and gas outburst [R], 2014. 